Original Research Article

\title{
A prospective observational study on drug safety monitoring and Pharmacoeconomics in patients with locally advanced unresectable NSCLC in a tertiary care hospital
}

\author{
Jayakumar Sreenivasan ${ }^{1}$, Seema P. Mohamedali ${ }^{2 *}$
}

${ }^{1}$ MBBS Student, ${ }^{2}$ Department of Pharmacology, Govt. Medical College, Kozhikode, Kerala, India

Received: 20 July 2017

Revised: 23 February 2018

Accepted: 27 February 2018

*Correspondence to:

Dr. Seema P. Mohamedali, Email: seemapharmac@ gmail.com

Copyright: (C) the author(s), publisher and licensee Medip Academy. This is an openaccess article distributed under the terms of the Creative Commons Attribution NonCommercial License, which permits unrestricted noncommercial use, distribution, and reproduction in any medium, provided the original work is properly cited.

\begin{abstract}
Background: Lung cancer is the deadliest type of cancer for both men and women. The study was aimed at learning and comparing the toxicities of various chemotherapeutic regimens for the treatment of carcinoma lung, which will help in the implementation of counter measures to avoid development of toxicities, with a constant vigil on the patients during chemotherapeutic cycles. This study also aimed at searching into the added economic burden to the unfortunate patient, who is already suffering from a deadly disease. Study also targeted at evaluating the performance status of the patients receiving the chemotherapy.

Methods: The Adverse Drug Reactions (ADR) data was collected from 40 patients receiving chemotherapy for locally advanced unresectable carcinoma lung from the cancer wards of a tertiary care hospital over a period of 2 months. ADRs were graded according to WHO guidelines and their performance statuses were assessed using the Zubrod's performance scale. Cost analysis of chemotherapeutic regimens was also carried out.

Results: On comparison, alopecia and peripheral neuropathy were significantly more common with carboplatin-paclitaxel combination compared to other regimens ( $\mathrm{p}$ value<0.005). Cost analysis reveals that the most commonly employed carboplatin-paclitaxel combination is more affordable when compared to the newer highly expensive agents but is costlier than cisplatin based chemotherapy. Also, carboplatin-paclitaxel combination offers a reasonably good performance status.

Conclusions: Thus, carboplatin-paclitaxel combination is the preferred regimen for palliation in advanced NSCLC, especially in the older patients.
\end{abstract}

Keywords: Adverse drug reaction, Chemotherapeutic agents, Cost analysis, Lung cancer, Performance status

\section{INTRODUCTION}

Lung cancer is the most common malignancy in both men and women constituting $12.3 \%$ of all cancers worldwide and is a leading cause of cancer related mortality amounting to 1.1 million deaths annually. ${ }^{1}$

Most lung cancers are diagnosed at an advanced stage conferring a poor prognosis.
NSCLC accounts for $85 \%$ of lung cancer. ${ }^{2}$ Almost $45 \%$ of them have clinically detectable metastasis at diagnosis. ${ }^{2}$ As the survival rate of carcinoma lung is very low, patients deserve a cost effective regimen with least adverse effects and which offers good quality of life for each day of life saved.

Current standard in the management of locally advanced unresectable NSCLC is combined modality treatment consisting of platinum based chemotherapy and radiation. 
Cisplatin is the most commonly used platinum compound. Apart from alkylating agents and platinum compounds, newer agents like camptothecins, taxanes, gemcitabine and vinorelbine have been used successfully in the treatment of carcinoma lung. ${ }^{3}$ The latest advancement is the introduction of molecular targeted agents like erlotinib and gefitinib. All anticancer drugs known to date are toxic for the tumour as well as the host. When the clinical goal is palliation, careful attention to minimize the toxicity becomes a significant goal. Thus one of the challenges of cancer treatment is to use the various treatment modalities in a manner that maximizes the chances for patient benefit. As carcinoma lung is the most common malignancy, this study is a focused monitoring of ADR profile of various chemotherapeutic regimens for the treatment of carcinoma lung in the cancer wards of our hospital.

Quality of life is an important prognostic factor in patients with cancer. This study also evaluates the performance status of the patients. Several scales for measuring Performance Status have been suggested, there is only limited information about the validity and reliability of these scales and hence this study used Zubrod's performance scale. ${ }^{4}$

The concept that health care expenditures are out of hand is not new. In a country like India, where the health insurance system is out of reach from the hands of most of the people, it is better to have a second thought over the cost per day of life saved and the expected outcome. Hence, the study assessed the affordability of the antineoplastic drugs prescribed.

The global rise in lung cancer incidence together with the fact that overall 5 year survival of patients with this disease is $<15 \%$, underscores the magnitude of lung cancer epidemic..$^{5}$ An evaluative study on adverse drug reaction profile of cisplatin-based chemotherapy regimen conducted at JIPMER, India assessed the causality by using the World Health Organization (WHO) causality assessment scale and Naranjo's Algorithm. ${ }^{6}$

The study reveals that cisplatin-based chemotherapy has a high potential to cause adverse effects and that most of the reactions were of milder nature but not preventable, but reactions like hypersensitivity reactions and anaphylaxis were not predictable. A feasibility study of paclitaxel 225 $\mathrm{mg} / \mathrm{m}^{2}$ and carboplatin $\mathrm{AUC}=6$ in untreated advanced NSCLC in Japan was designated to determine whether paclitaxel is tolerable for Japanese patients with advanced NSCLC. ${ }^{7}$

An interventional study on the effect of cyclophosphamide on advanced lung cancer and the hematological toxicity of large, intermittent intravenous doses conducted in Toronto, Canada was done to determine the maximally tolerated single intra-venous dose of cyclophosphamide, the interval required for marrow recovery, the frequency of objective tumor regression and the effect of this therapy on the survival of patients with advanced lung cancer. ${ }^{8}$
A prospective observational comparative study of the toxicity of 5-fluorouracil-adriamycin-cyclophosphamide (FAC) versus adriamycin- cyclophosphamide followed by paclitaxel (AC-P) in carcinoma breast analyzed the severity of different types of toxicities seen in patients on FAC and AC-P regimens and graded the toxicities according to the World Health Organization (WHO) toxicity grading and compared the same. ${ }^{9}$

\section{METHODS}

This prospective observational study was carried out among the inpatients of the cancer wards of a tertiary care hospital, during the months of June and July 2011. A total of 40 patients were included in the study after satisfying the inclusion criteria.

\section{Inclusion criteria}

- Cancer patients belonging to either gender, age groups between 40 to 80 years.

- $\quad$ All the patients diagnosed to have locally advanced unresectable NSCLC (stages II, IIIa and IIIb) receiving chemotherapy under any standard regimen irrespective of any prior surgery or other interventions. All patients in stage IV were also included in the study because almost $45 \%$ of the NSCLC cases have clinically detectable metastasis at diagnosis.

\section{Exclusion criteria}

- Those who were not willing to participate in the study.

- $\quad$ Those with NSCLC of stage I

- All other forms of carcinoma lung.

Institutional Ethics Committee approval was obtained initially. After obtaining an informed written consent, all patients satisfying the entry criteria were enrolled in the study. The patients received chemotherapy as per the assessment of the treating oncologist. No changes in the treatment decision schedule or duration were made as a part of the study. The patients admitted for receiving chemotherapy were monitored for adverse effects till their discharge from the hospital.

All the patients were assessed during the course of chemotherapy and observed for the immediate occurrence of any of the toxicities. The patients were personally interviewed for subjective toxicities such as nausea, vomiting, and the like and their toxicity grades were assessed. The toxicities like anaemia, leukopenia, and thrombocytopenia were assessed based on the investigations done. The patients were clinically examined for other toxicities like alopecia, peripheral neuropathy, and other dermatological toxicities.

All the data collected were entered in the proforma sheet and analyzed for demographic details, drug details and 
severity of adverse reactions. The toxicities developed were to be graded according to the WHO guidelines. The WHO grades toxicities into five ascending grades, which are, Grades 0, 1, 2, 3, and 4. Grade 0 represents normal values or absence of toxicity, whereas; grade 4 represents maximum toxicity that can occur for a variable, except for alopecia where grade 2 is the highest toxicity (complete hair loss). Data analysis was done with the help of the MS Excel and SPSS statistical software. The toxicity grades were entered in the MS Excel worksheet for each variable. The Student's t test was used to assess the difference between various regimens. The plan to use chi square test was dropped because of the great difference between the number patients in each group receiving different chemotherapeutic regimens. Student's t test is a better tool available in SPSS to analyze such data. The performance status was assessed using the Zubrod's performance scale.

Using the proforma, the details of pharmacotherapy including the brand name of the drug, its frequency, dosage, the number of cycles per course and number of days per cycle of the chemotherapeutic regimen were collected. The drugs included not only the antineoplastic drugs but also, the adjuvant drugs given as part of the regimen to reduce the known and expected adverse effects. The total expenditure for a course of each chemotherapeutic schedule was calculated with reference to CIMS (Current Index of Medical Specialties) April July 2011 update 2 . The obtained data was used to analyze the cost effectiveness of each regimen.

\section{RESULTS}

A total of 40 patients who were admitted for lung cancer chemotherapy after histo pathologically being proven for Non-small cell carcinoma were allocated for the study.

The age range of patients included in the study was between 40 and 80 years with a mean age of 57 years. Most of the patients fell in the age group 50-60 years. $92.5 \%$ of the patients were males; that is out of the total 40 patients, only three were females. $90 \%$ of the study population was from rural area. Also $92.5 \%$ of the patients belong to low socioeconomic status. $82.5 \%$ of the patients were found to be smokers and out of these one was female. $94 \%$ of the smokers had smoking history with significant number of pack years.

Classification of patients based on histology showed that 15 of them $(38 \%)$ had adenocarcinoma, $13(33 \%)$ had squamous cell carcinoma and remaining was constituted by other types. Out of the 40 patients under the study, 26 $(65 \%)$ were given carboplatin and paclitaxel combination chemotherapy, 5 (12\%) were given cyclophosphamidecisplatin regimen, and another $4(10 \%)$ were given cisplatin-paclitaxel. Rest of them were given gefitinib $(5 \%)$, gemcitabine-carboplatin $(3 \%)$ and pemetrexedcisplatin $(5 \%)$. (Figure 1)

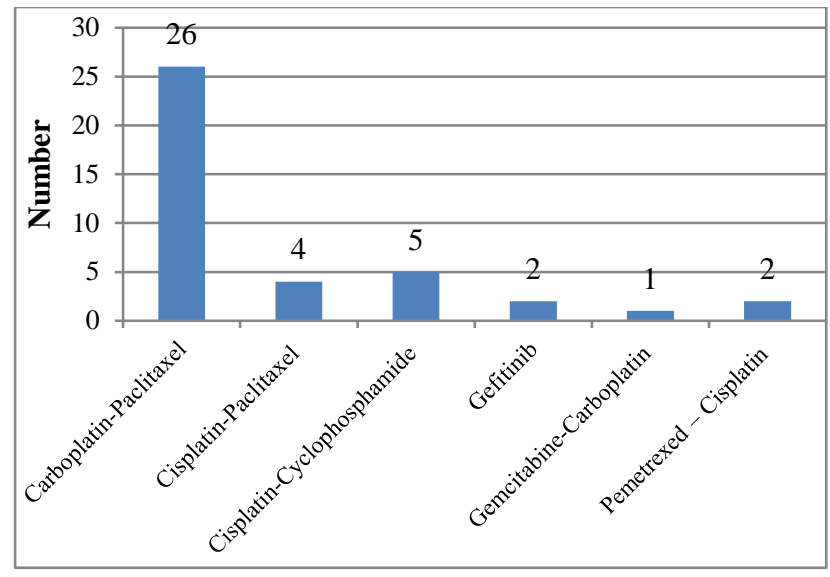

Figure 1: Distribution of various chemotherapeutic regimens among the study population.

Overall analysis of adverse drug reactions in patients who received above regimens revealed that not even a single patient was completely free of any adverse drug reactions (Table 1).

The most frequent adverse reactions were myelosuppression, alopecia, peripheral neuropathy and nausea. Others include vomiting, tinnitus, vertigo, and stomatitis.

$96 \%$ of patients receiving carboplatin- paclitaxel had alopecia. All of them had grade 2 alopecia (i.e., $>50 \%$ hair loss). All the 4 patients $(100 \%)$ receiving cisplatinpaclitaxel also had alopecia whereas only one out of 5 patients $(20 \%)$ receiving cyclophosphamide - cisplatin was reported to have this adverse reaction (that too grade 1). Newer agents caused little or no alopecia. 37 patients had myelosuppression in one or the other way (Table 2).

$58 \%$ of patients on carboplatin-paclitaxel had anaemia, most of which was either of grade 1 or grade 2 . One patient had grade 4 anaemia, which needed packed RBC transfusion. Also, $15 \%$ of patients on this regimen had neutropenia and $19 \%$ had thrombocytopenia. Three of them with neutropenia required intravenous Filgrastim (is a granulocyte colony-stimulating factor (G-CSF) analog used to stimulate the proliferation and differentiation of granulocytes) and 2 patients, one with grade 3 and the other with grade 4 thrombocytopenia required administration of platelet rich plasma.

There were three out of 4 patients $(75 \%)$ on cisplatinpaclitaxel had mild anaemia. None of them experienced neutropenia and 1 patient had thrombocytopenia. 4 out of 5 patients $(80 \%)$ on cyclophosphamide - cisplatin had anaemia, one of whom had grade 4 anaemia which was managed by packed RBC.

Newer agents like gefitinib, pemetrexed and gemcitabine combinations were almost free of myelosuppression. 
Table 1: Summary of ADR profile of chemotherapeutic regimens.

\begin{tabular}{|llllllll|}
\hline & $\begin{array}{l}\text { Carboplatin } \\
\text {-paclitaxel } \\
(\mathbf{2 6})\end{array}$ & $\begin{array}{l}\text { Cisplatin- } \\
\text { paclitaxel } \\
(\mathbf{4})\end{array}$ & $\begin{array}{l}\text { Cyclophosphami } \\
\text { de-cisplatin } \\
(\mathbf{5})\end{array}$ & $\begin{array}{l}\text { Gefitinib } \\
(\mathbf{1})\end{array}$ & $\begin{array}{l}\text { Gemcitabine- } \\
\text { carboplatin } \\
(\mathbf{2})\end{array}$ & $\begin{array}{l}\text { Pemetrexed } \\
\text {-cisplatin } \\
(\mathbf{1})\end{array}$ & $\begin{array}{l}\text { Total } \\
(\mathbf{4 0})\end{array}$ \\
\hline Nausea & 14 & 0 & 1 & 0 & 0 & 1 & 20 \\
\hline Vomitting & 5 & 0 & 0 & 0 & 1 & 7 \\
\hline Alopecia & 25 & 4 & 0 & 0 & 0 & 0 & 1 \\
\hline $\begin{array}{l}\text { Elevated } \\
\text { S.Urea }\end{array}$ & 1 & 0 & 0 & 0 & 0 & 0 & 1 \\
\hline $\begin{array}{l}\text { Elevated S. } \\
\text { Creatinine }\end{array}$ & 1 & 0 & 0 & 0 & 0 & 0 & 19 \\
\hline $\begin{array}{l}\text { Peripheral } \\
\text { neuropathy }\end{array}$ & 17 & 1 & 1 & 0 & 0 & 0 & 5 \\
\hline Tinnitus & 5 & 0 & 0 & 0 & 0 & 0 & 4 \\
\hline Vertigo & 4 & 0 & 0 & 0 & 1 & 2 & 25 \\
\hline Anaemia & 15 & 3 & 4 & 0 & 1 & 0 & 5 \\
\hline Neutropenia & 4 & 0 & 0 & 0 & 0 & 0 & 7 \\
\hline $\begin{array}{l}\text { Thrombocyt } \\
\text { openia }\end{array}$ & 5 & 1 & 1 & 1 & 0 & 0 & 2 \\
\hline Diarrhoea & 1 & 0 & 0 & 1 & 0 & 0 & 1 \\
\hline Skin rashes & 0 & 0 & 0 & 0 & 0 & 0 & 7 \\
\hline Stomatitis & 7 & 0 & 0 & 0 & 0 & 0 & 0 \\
\hline $\begin{array}{l}\text { Hyper- } \\
\text { sensitivity }\end{array}$ & 0 & 0 & 0 & 0 & 0 & 0 & 0 \\
\hline Arrhythmia & 0 & 0 & 0 & 0 & 0 & 0 & 0 \\
\hline ILD & 0 & 0 & 0 & & & 0 \\
\hline
\end{tabular}

Table 2: Statistically significant differences ( $p$ value $<0.005$ ) in the toxicity profile of various chemotherapeutic regimens as analysed by the student's $\mathrm{t}$ test.

\begin{tabular}{|c|c|c|c|c|}
\hline Regimen & No. & $\begin{array}{l}\text { Adverse } \\
\text { reactions }\end{array}$ & Mean & $\begin{array}{l}\mathbf{P} \\
\text { value }\end{array}$ \\
\hline $\begin{array}{l}\text { Carboplatin } \\
\text { paclitaxel }\end{array}$ & 26 & \multirow{2}{*}{ Alopecia } & 1.92 & \multirow{2}{*}{0.000} \\
\hline $\begin{array}{l}\text { Other } \\
\text { regimens }\end{array}$ & 14 & & 0.67 & \\
\hline $\begin{array}{l}\text { Carboplatin } \\
\text { paclitaxel }\end{array}$ & 26 & \multirow{2}{*}{$\begin{array}{l}\text { Peripheral } \\
\text { neuropathy }\end{array}$} & 0.77 & \multirow{2}{*}{0.004} \\
\hline $\begin{array}{l}\text { Other } \\
\text { regimens }\end{array}$ & 14 & & 0.20 & \\
\hline $\begin{array}{l}\text { Cisplatin } \\
\text { paclitaxel }\end{array}$ & 5 & \multirow{3}{*}{ Alopecia } & 1.75 & \multirow{3}{*}{0.002} \\
\hline Cisplatin & & & & \\
\hline $\begin{array}{l}\text { cyclophospha } \\
\text { mide }\end{array}$ & 4 & & 0.20 & \\
\hline
\end{tabular}

Nausea and vomiting though frequent were relatively mild in severity. Out of the 20 reported cases of nausea, 14 were in patients on carboplatin-paclitaxel. Three out of 4 patients on cyclophosphamide - cisplatin experienced nausea. Five cases of vomiting were reported from patients on carboplatin-paclitaxel and one case each from patients on cyclophosphamide - cisplatin and pemetrexed-cisplatin.
$65 \%$ of patients on carboplatin-paclitaxel were suffering from peripheral neuropathy, which were of grade 1 or 2 . Cases of peripheral neuropathy were also reported one each from patients on cisplatin- paclitaxel and cyclophosphamide - cisplatin (Table 2).

Stomatitis was reported only from patients on carboplatinpaclitaxel, accounting for $27 \%$ of cases on this regimen.

One case each of elevated serum creatinine and serum urea level was reported from patients on carboplatin-paclitaxel. Other notable adverse drug reactions like tinnitus (19\%) and vertigo $(15 \%)$ were also suffered by patients on this regimen.

One case each of diarrhoea and skin rash was reported from patients on gefitinib. The reported case of diarrhoea was grade 4 which required parenteral fluid administration. Other adverse reactions reported include skin pigmentation, itching and constipation.

Incidence of alopecia and peripheral neuropathy were significantly higher in patients who received carboplatinpaclitaxel compared to all other regimens. Similarly, alopecia was less frequent when cisplatin was combined with cyclophosphamide than when it is combined with Paclitaxel. 


\section{Table 3: Comparative evaluation of Zubrod's performance status of major chemotherapeutic regimens.}

\begin{tabular}{|c|c|c|c|}
\hline REGIMEN & $\mathbf{N}$ & MEAN & P value \\
\hline Carboplatin paclitaxel & 26 & 2.27 & \multirow{2}{*}{0.960} \\
\hline Cisplatin paclitaxel & 4 & 2.25 & \\
\hline Cisplatin paclitaxel & 4 & 2.25 & \multirow[b]{2}{*}{0.136} \\
\hline $\begin{array}{l}\text { Cisplatin } \\
\text { cyclophosphamide }\end{array}$ & 5 & 1.40 & \\
\hline Carboplatin paclitaxel & 26 & 2.27 & \multirow[b]{2}{*}{0.011} \\
\hline $\begin{array}{l}\text { Cisplatin } \\
\text { cyclophosphamide }\end{array}$ & 5 & 1.40 & \\
\hline Carboplatin paclitaxel & 26 & 2.27 & \multirow{2}{*}{0.007} \\
\hline Other regimens & 14 & 1.60 & \\
\hline
\end{tabular}

When the Zubrod's performance status of various regimens were analyzed, significant difference in the performance was obtained when carboplatin - paclitaxel was compared with other regimens altogether $(\mathrm{P}$ value $=$ 0.007). Mean Zubrod's status for patients who received carboplatin paclitaxel combination chemotherapy was 2.27 and that for other regimens altogether was 1.60 (Table 3). Combining these parameters along with the cost analysis (Table 4) of each regimen, the Cost-Performance Ratio and Performance-ADR score Ratio was obtained. The regimen with least value for these ratios will be the preferred chemotherapeutic combination.

Table 4: Cost analysis of chemotherapeutic regimens.

\begin{tabular}{|ll|}
\hline Regimen & $\begin{array}{l}\text { Cost of one course } \\
\text { of chemotherapy }\end{array}$ \\
\hline $\begin{array}{l}\text { Carboplatin-Paclitaxel } \\
\text { combination }\end{array}$ & Rs.25,699/- \\
\hline Cisplatin-Cyclophosphamide & Rs.6,256/- \\
\hline Cisplatin-Paclitaxel & Rs.18,310/- \\
\hline Carboplatin-Gemcitabine & Rs.69,951/- \\
\hline Gefitinib & Rs.54,000/- \\
\hline Cisplatin-Pemetrexed & Rs.120992/- \\
\hline
\end{tabular}

\section{DISCUSSION}

Non-small cell Lung cancer occurs predominantly in people aged 50-70 years. ${ }^{2}$ In this study, most of the patients fell in the age group of 50-60 years. $92.5 \%$ of the patients were males; that is out of the total 40 patients, only three were females. According to Indian statistics, 75\% lung cancer occurs in men. ${ }^{1}$ Globally $85 \%$ cases in men and $46 \%$ cases in women are due to smoking. ${ }^{10}$ In this study $82.5 \%$ of the patients were found to be smokers and out of these one was female. Squamous cell carcinoma was more common in men than in women and is closely correlated with smoking history. ${ }^{11}$ So in this study where almost all have significant smoking history, histological type squamous cell carcinoma was expected to be the most common. But adenocarcinoma was the most common histological type diagnosed. This is in accordance with the recent trend of increasing incidence of adenocarcinoma.
Multiple randomized, controlled trials and large metaanalyses all confirm the superiority of combination chemotherapy regimens upfront for advanced non-small cell lung cancer. ${ }^{12}$ Cisplatin has been the cornerstone of most combination regimens. ${ }^{13}$ In younger patients, with a good performance status or in the adjuvant setting, cisplatin is preferred, but in older patients or those with significant co morbidities, carboplatin may be substituted. One of the new potentially useful agents to treat advanced NSCLC is paclitaxel. As a single agent in early phase II trials, paclitaxel produced a $20 \%$ to $24 \%$ response rate and a 1-year survival rate as high as $42 \% .{ }^{14,15}$ Accordingly, 26 cases $(65 \%)$ of carboplatin-paclitaxel combination and 4 cases $(10 \%)$ of cisplatin- paclitaxel combination are reported in this study. A study conducted in Japan for the adverse reactions of carboplatin-paclitaxel combination therapy, Grade 4 neutropenia was observed in $70 \%$ of the patients, $100 \%$ patients suffered from anaemia and grade 4 anaemia was experienced by $20 \%$ of patients. $15 \%$ of patients who received this regimen suffered neutropenia, $58 \%$ experienced anaemia out which $12 \%$ had grade 3 or 4. $19 \%$ patients experienced thrombocytopenia and $8 \%$ of them had grade 3 or 4 thrombocytopenia. Nonhaematological toxicities in all courses were mild. Clinically significant hypersensitivity reactions were not observed. Nausea or vomiting was observed in $70 \%$ patients. Alopecia was common. There were no cardiac toxicities related to paclitaxel. $100 \%$ patients experienced peripheral neuropathy, but $10 \%$ patients had grade 3 . Arthralgia were observed in $80 \%$ but was grade 2 or less. Regarding the non haematological toxicities, comparable result was obtained in this study also, except that arthralgia was not reported and $4 \%$ cases had elevated serum creatinine and serum urea levels, tinnitus (19\%) and vertigo $(15 \%)$. The most frequent toxicities produced by short term infusion of the paclitaxel - carboplatin regimen were leukopenia and neutropenia in the Japan based study. But in this study, this was only seen in $15 \%$ of the patients. This is also incompatible with the South West Oncology Group's (SWOG) data, which showed $36 \%$ of 188 patients. ECOG reported that $42 \%$ of 272 patients showed grade 4 neutropenia, whereas the Hellenic Cooperative Oncology Group reported that only $1 \%$ of 99 patients showed grade 4 neutropenia. ${ }^{4,16,17}$ These data from different studies indicate a widely ranging incidence of neutropenia. Other studies have reported peripheral neuropathy, arthralgia and myalgia to be dose limiting toxicities when paclitaxel was combined with either cisplatin or carboplatin. ${ }^{18}$ In this study, these toxicities were relatively mild. Moreover, these toxicities were reversible. An evaluative study on adverse drug reaction profile of cisplatin-based chemotherapy conducted at JIPMER, Pondicherry observed that $51 \%$ developed alopecia, $41 \%$ developed vomiting and no hematological toxicities. ${ }^{6}$ A study by Bahl et al, on 40 patients with locally advanced non-small cell lung cancer, treated with cisplatin and etoposide, the frequency of alopecia was reported as $88 \% .{ }^{19}$ Sensory neuropathy was seen in $38 \%$ of patients and is comparable to $25 \%$ in this study. Anaemia was the most common haematological toxicity 
observed (seen in $81 \%$ of patients) and is consistent with $75 \%$ here. A French article on investigation of allergic reactions to platinum compounds reports anaphylactic reaction to cisplatin and carboplatin after several courses of treatment. ${ }^{20}$ However, no such incidence was reported in this study. Thus, comparison between the toxicity profile of cisplatin and carboplatin reveals a slightly greater incidence of myelosuppression, nephrotoxicity, ototoxicity, peripheral neuropathy and stomatitis for carboplatin. But the average ADR score, carboplatin based combination wins upper hand. An individual patient data meta-analysis suggests that cisplatin-based chemotherapy is slightly superior to carboplatin-based chemotherapy in terms of response rate and in prolonging survival. ${ }^{21} \mathrm{~A}$ retrospective evaluation of the results of cyclophosphamide therapy conducted at the University of Wisconsin Hospitals reports that all patients were treated for leukopenia. ${ }^{22}$ A single death was attributed to leukopenia and pneumonitis. Alopecia was common and occurred in all the cases. Cystitis occurred in six patients on oral cyclophosphamide but not in the 42 patients who received only intravenous therapy. In this study, 5 patients received cisplatin-cyclophosphamide combination chemotherapy. Akin to the earlier study, nausea and vomiting was mild with the present study also, no reported cases of neutropenia, $80 \%$ developed anaemia, of which one had grade 4 anaemia. Thrombocytopenia was of less severity with a single reported case, only $20 \%$ developed alopecia and that too was of grade 1, peripheral neuropathy was seen in a patient (grade1). A study comparing cyclophosphamide and cisplatin with paclitaxel and cisplatin in patients with Stage III and Stage IV Ovarian Cancer has found that statistically significant difference in the adverse effects with more toxicity in the cisplatinpaclitaxel group. ${ }^{23}$ There was no incidence of neutropenia with both these regimens and the incidence of peripheral neuropathy was almost same here.

Newer drug in this study include gemcitabine, gefitinib and pemetrexed. Gemcitabine, because of its acceptable toxicity profile, with myelosuppression being the most common adverse event, can be safely combined with a number of cytotoxic agents, including platinum derivatives and new-generation anticancer compounds. ${ }^{24}$ Myelosuppression is evident in this study as the only reported side effect being anaemia and neutropenia. Several phase I studies of single-agent pemetrexed have evaluated different dosing schedules. ${ }^{25}$ Reversible neutropenia was the dose-limiting toxicity (DLT). In this study, anaemia was reported in both the patients on pemetrexed. Patients receiving gefitinib had a higher response rate ( $43 \%$ vs. $32 \%$ ), with similar median survival. Patients who were positive for the EGFR gene mutation had significantly longer progression-free survival in the gefitinib group compared with those who received carboplatin-paclitaxel. ${ }^{26}$ The apparent inferiority of the most commonly used carboplatin-paclitaxel combination chemotherapy on comparing the Zubrod's performance status may be attributed to the fact that this regimen is preferably employed on terminally ill elderly patients, with main focus on palliation. Also the newer agents like gefitinib, gemcitabine and pemetrexed offer a better quality of life.

Cost analysis revealed that the novel drugs which are safer and efficient are much more costly than the frequently used chemotherapeutic regimens. Among the commonly used regimens, there is significant difference between the costs of carboplatin-paclitaxel and cisplatin-cyclophosphamide regimens. Cisplatin-paclitaxel costs about three times higher than cyclophosphamide-cisplatin regimen and carboplatin based regimen is even costlier.

Our institution being depended upon by the economically deprived rural population, platinum compound based therapy remains the mainstay for lung cancer. Average ADR score was much higher in patients on cisplatinpaclitaxel than on carboplatin- paclitaxel combination. Also there was no significant difference between cyclophosphamide based therapy and carboplatinpaclitaxel combination. This shows that the above two regimens are the better tolerated combinations. Average Zubrod's Performance score was best with cyclophosphamide-cisplatin combination whereas it was almost the same and less favourable with the cisplatinpaclitaxel and carboplatin-paclitaxel combinations.

Combining these parameters along with the cost analysis of each regimen, the Cost-Performance Ratio and Performance-ADR score Ratio was obtained. The regimen with least value for these ratios will be the preferred chemotherapeutic combination. In such a way, the best option to choose is the cyclophosphamide-cisplatin combination chemotherapy. This is in contrast to the fact that the carboplatin - paclitaxel regimen is the preferentially prescribed regimen for the population under this study. This may be because of the fact that there is no evidence that life was prolonged by the cyclophosphamide based regimen and also the available literature being strongly supportive of the increased survival in patients on carboplatin-paclitaxel combination chemotherapy.

\section{CONCLUSION}

To conclude, most of the study findings were consistent with the data available in the literature. Only a few statistically significant differences were observed .On comparison, alopecia and peripheral neuropathy were significantly more common with carboplatin-paclitaxel combination compared to other regimens ( $p$ value $<0.005$ ). Cost analysis reveals that the most commonly employed carboplatin-paclitaxel combination is more affordable when compared to the newer highly expensive agents but is costlier than cisplatin based chemotherapy. Also, carboplatin-paclitaxel combination offers a reasonably good performance status. Since this is a short term study, long term studies are worth doing to substantiate these findings.

Funding: No funding sources 
Conflict of interest: None declared

Ethical approval: The study was approved by the Institutional Ethics Committee

\section{REFERENCES}

1. K Park. Park's textbook of Preventive and Social Medicine 20th Edition, M/s Banarsidas Bhanot publishers; 2011:360-370.

2. Stephen J. McPhee, Maxine A. Papadakis, Eds. Michael W. Rabow, Associate Ed. CURRENT Medical Diagnosis and Treatment. The McGraw-Hill Companies, Inc. 2011.

3. Karnofsky DA, Ableman WH, Craver LF, Burchenal JH. The use of nitrogen mustard in the palliative treatment of carcinoma. Cancer. 1948;1:634-56.

4. Zubrod CG, Schneiderman M, Frei E, Brindley C, Gold GL, Shnider B, et al. Appraisal of methods for the study of chemotherapy of cancer in man: comparative therapeutic trial of nitrogen mustard and triethylene thiophosphoramide. Journal of Clinical Epidemiology. 1960 Jan 1;11(1):7-33.

5. Vincent T DeVita, Jr. MD Theodore S Lawrence MD, PhD Steven A Rosenberg MD, PhD Ronald A DePinho MD Robert A Weinberg PhD. DeVita, Hellman, and Rosenberg's Cancer: Principles and Practice of Oncology: Lippincott Williams and Wilkins; 2011.

6. Surendiran A, Balamurugan N, Gunaseelan K, Akhtar S, Reddy KS, Adithan C. Adverse drug reaction profile of cisplatin-based chemotherapy regimen in a tertiary care hospital in India: An evaluative study. Indian journal of pharmacology. $2010 \mathrm{Feb}$;2(1):40.

7. Ogawara M, Kawahara M, Hosoe S, Atagi S, Kawaguchi T, Okishio K, et al. A Feasibility Study of Paclitaxel $225 \mathrm{mg} / \mathrm{m} 2$ and Carboplatin $\mathrm{AUC}=6$ in Untreated Advanced Non-small Cell Lung Cancer Patients in Japan. Japanese Journal of Clinical Oncology. 2002 Feb 1;32(2):48-53.

8. Bergsagel DE, Robertson GL, Hasselback R. Effect of cyclophosphamide on advanced lung cancer and the hematological toxicity of large, intermittent intravenous doses. Canadian Medical Association Journal. 1968 Mar 16;98(11):532.

9. Palappallil DS, Nair BL, Jayakumar KL, Puvathalil RT. Comparative study of the toxicity of 5fluorouracil-adriamycin-cyclophosphamide versus adriamycin-cyclophosphamide followed by paclitaxel in carcinoma breast. Indian Journal of Cancer. 2011 Jan 1;48(1):68.

10. Torre DM, Lamb GC, Van Ruiswyk J, Schapira RM, Kochar MS. Kochar's Clinical Medicine for Students: Lippincott Williams and Wilkins; Feb 13, 2008.

11. Sørensen JB, Klee M, Palshof T, Hansen HH. Performance status assessment in cancer patients. An inter-observer variability study. British Journal of Cancer. 1993 Apr;67(4):773.

12. Delbaldo C, Michiels S, Syz N, Soria JC, Le Chevalier T, Pignon JP. Benefits of adding a drug to a singleagent or a 2-agent chemotherapy regimen in advanced non-small-cell lung cancer: a meta-analysis. JAMA. Jul 28 2004; 292(4):470-84.

13. Weick JK, Crowley J, Natale RB, Hom BL, Rivkin S, Coltman Jr CA, et al. A randomized trial of five cisplatin-containing treatments in patients with metastatic non-small-cell lung cancer: A Southwest Oncology Group study. Journal of Clinical Oncology. 1991 Jul;9(7):1157-62.

14. Murphy WK, Fossella FV, Winn RJ, Shin DM, Hynes HE, Gross HM, et al. Phase II study of taxol in patients with untreated advanced non-small-cell lung cancer. JNCI: Journal of the National Cancer Institute. 1993 Mar 3;85(5):384-8.

15. Chang AY, Kim K, Glick J, Anderson T, Karp D, Johnson D. Phase II study of taxol, merbarone, and piroxantrone in stage IV non-small-cell lung cancer: The Eastern Cooperative Oncology Group Results. JNCI: Journal of the National Cancer Institute. 1993 Mar 3;85(5):388-94.

16. Shiller JH, Harrington D, Sandler A, Belani C, Langer C, Krook J, et al. A randomized phase III trial of four chemotherapy regimens in advanced non-small cell lung cancer (NSCLC). Proc Am Soc Clin Oncology. 2000;19:1a (abstr 2).

17. Kosmidis P, Mylonakis N, Skarlos D, Samantas E, Dimopoulos M, Papadimitriou C, et al. Paclitaxel (175 $\mathrm{mg} / \mathrm{m} 2$ ) plus carboplatin (6 AUC) versus paclitaxel $(225 \mathrm{mg} / \mathrm{m} 2)$ plus carboplatin (6 AUC) in advanced non-small-cell lung cancer (NSCLC): a multicenter randomized trial. Ann Oncology. 2000;11:799-805.

18. Natale RB. Preliminary results of a phase I/II clinical trial of paclitaxel and carboplatin in non-small cell lung cancer. Semin Oncology. 1996;23(16):51-64.

19. Bahl A, Sharma DN, Julka PK, Rath GK. Chemotherapy related toxicity in locally advanced non-small cell lung cancer. J Cancer Res Ther. 2006;2:14-6.

20. Touraine F, Sainte JL, Boumédiène A, Ndikumwenayo F, Decroisette C, Melloni B, et al. Investigation of allergic reactions to platinum salts. Revue des maladies respiratoires. 2006 Nov;23(5 Pt 1):458-62.

21. Ardizzoni A, Boni L, Tiseo M, Fossella FV, Schiller JH, Paesmans M, et al. Cisplatin-versus carboplatinbased chemotherapy in first-line treatment of advanced non-small-cell lung cancer: an individual patient data meta-analysis. Journal of the National Cancer Institute. 2007 Jun 6;99(11):847-57.

22. Davis HL, Ramirez G, Korbitz BC, Ansfield FJ. Advanced lung cancer treated with cyclophosphamide. Diseases of the Chest. 1969 Dec 1;56(6):494-500.

23. McGuire WP, Hoskins WJ, Brady MF, Kucera PR, Partridge EE, Look KY, et al. Cyclophosphamide and cisplatin compared with paclitaxel and cisplatin in patients with stage III and stage IV ovarian cancer. New England Journal of Medicine. 1996 Jan 4;334(1):1-6. 
24. Toschi L, Cappuzzo F. Dovepress Journal: Onco Targets and Therapy. Gemcitabine for the treatment of advanced non-small cell lung cancer. 2009;2:209-217.

25. Rinaldi DA, Burris HA, Dorr FA, Woodworth JR, Kuhn JG, Eckardt JR, et al. Initial phase I evaluation of the novel thymidylate synthase inhibitor, LY231514, using the modified continual reassessment method for dose escalation. Journal of clinical oncology. 1995 Nov;13(11):2842-50.

26. Mok TS, Wu YL, Thongprasert S, Yang CH, Chu DT, Saijo N, et al. Gefitinib or carboplatin-paclitaxel in pulmonary adenocarcinoma. N Engl J Med. Sep 3 2009;361(10):947-57.

Cite this article as: Sreenivasan J, Mohamedali SP. A prospective observational study on drug safety monitoring and Pharmacoeconomics in patients with locally advanced unresectable NSCLC in a tertiary care hospital. Int J Basic Clin Pharmacol 2018;7:67683. 